\title{
A ADAPTAÇÃO TRANSCULTURAL EM OS SETE AFLUENTES DO RIO OTA DE ROBERT LEPAGE
}

\author{
Danielle Cristine Fullan ${ }^{1}$
}

\begin{abstract}
Resumo: Robert Lepage é conhecido pela mescla de diferentes dispositivos midiáticos e o uso de outras manifestações artísticas para a composição de suas produções. A peça Os Sete Afluentes do Rio Ota, por exemplo, pode ser considerada um produto intermidiático por excelência, a partir do diálogo que estabelece com a ópera Madama Butterfly. Este artigo analisa essa relação especialmente sob o ponto de vista da adaptação transcultural proposto por HUTCHEON (2006).
\end{abstract}

Palavras-chave: Robert Lepage, Madama Butterfly, intermidialidade, adaptação transcultural.

\section{L'ADAPTATION TRANSCULTURELLE DANS LES SEPT BRANCHES DE LA RIVIERE OTA DE ROBERT LEPAGE}

Résumé: Robert Lepage est connu par le mélange de différents dispositifs de médias et l'utilisation d'autres expressions artistiques pour la composition de ses productions. La pièce Les Sept Branches de la rivière Ota, par exemple, peut être considére comme un produit intermédiatique par excellence, grâce au dialogue établi avec l'ópera Madama Butterfly. Cet article analyse cette relation en particulier du point de vue de l'adaptation transculturelle proposé par HUTCHEON (2006).

Mots-clés: Robert Lepage, Madama Butterfly, intermédialité, adaptation transculturelle

\section{Introdução}

O trabalho de Lepage costuma ser primeiramente reconhecido pelo uso que ele faz da tecnologia em suas produções. Não podemos esquecer também da forte influência em seu trabalho vinda de obras que o antecederam, independentemente do meio o qual foram produzidas. Se o 1 Mestranda em Estudos Linguísticos. Universidade Federal de Minas Gerais - UFMG. Endereço
Eletrônico: danifullan@gmail.com 
título da peça Os Sete Afluentes do Rio Ota, veio de um diálogo ${ }^{2}$ do filme Hiroshima, mon amour, de Alain Resnais, não é de se estranhar, portanto, que ele tenha conseguido extrair da ópera Madama Butterfly, de Giácomo Puccini, aspectos que coloquem a história do início do século $\mathrm{XX}$ ao centro de discussões muito mais profundas, como a bomba atômica e o Holocausto, por exemplo. O objetivo deste artigo é analisar o espetáculo Os Sete Afluentes do Rio Ota e apontar a aproximação intercultural que Lepage realiza especialmente entre o Ocidente e o Oriente utilizando-se para isso da transposição intersemiótica e da adaptação transcultural de Madama Butterfly.

\section{A peça Os sete afluentes do rio ota}

Criada para o $50^{\circ}$ aniversário da destruição das cidades japonesas de Hiroshima e Nagasaki, a peça Os Sete Afluentes do Rio Ota foi encenada pela primeira vez em 1995 em uma apresentação de três horas. Como Lepage privilegia o conceito de obra em andamento, a peça sofreu várias modificações de conteúdo e tempo, até chegar em 1996 à sua versão final, com oito horas de espetáculo. Esta é a versão que foi publicada e é este o texto que serviu de base para esta análise. Vale lembrar que em 2003 a obra foi montada no Brasil sob a co-direção de Monique Gardemberg e Michelle Matalon.

Sobre o desafio de criar o espetáculo, Lepage conta que este surgiu após uma visita à cidade de Hiroshima e sua surpresa ao ver o poder de renascimento, sobrevivência e de surpreendente sensualidade que ali existiam. De volta ao Canadá, reuniu-se com a equipe do Ex Machina ${ }^{3}$, momento em que acrescentaram diversas referências que direta ou indiretamente foram incorporadas à peça:

Sete caixas, sete afluentes, sete portas de correr japonesas, uma casa, um jardim (...) a isso se somaria o pressentimento de presença dos campos de

\footnotetext{
2 "Os sete afluentes do Rio Ota esvaziam-se e enchem-se com água fresca e piscosa, cinza ou azul, conforme a hora e a estação."

${ }^{3}$ Em 1993, ao deixar a direção artística do Centro Nacional de Artes, em Otawa, Robert Lepage decide estabelecer-se no Quebec, formando, com seus colaboradores, a companhia Ex Machina, que reúne artistas multidisciplinares em torno do fazer teatral.
} 
Dividido em sete quadros - numa referência aos setes afluentes do rio Ota, que corta a cidade de Hiroshima ${ }^{5}$, a peça é um épico que atravessa a metade final do século XX abordando os ataques da bomba atômica, o Holocausto, a AIDS, a homossexualidade e outros grandes dilemas da condição humana por meio de histórias de devastação e renascimento dos personagens Luke, Nozomi, Jeffrey 1, Jeffrey 2, Ada, Hanako, David, Jana, Sarah, Maurice, Sophie, Walter, Patrícia e Pierre.

As relações interpessoais desses personagens atravessa três continentes e se cruzam a todo instante, seja em Hiroshima, que pode ser considerada a espinha dorsal do espetáculo porque é lá que tudo (re)começa; Seja em Nova York, quando Jeffrey 2 descobre que é irmão de Jeffrey 1; Em Amsterdam, quando Jeffrey 1, aidético em estágio avançado, casa-se com Ada Weber para obter acesso à eutanásia; Seja na República Tcheca, quando Jana viaja no tempo para rememorar sua amizade com Sarah num campo de concentração; Osaka, em que um problema literal na tradução revela a incomunicabilidade pessoal de Sophie, Patrícia e Walter; Ou, quando o canadense Pierre chega a Hiroshima para estudar a dança japonesa e envolvese com David e Hanako.

Em citações diretas ou em subtextos é possível detectar algo da narrativa de Madama Butterfly em toda a história de Os Sete Afluentes do Rio Ota. É especialmente esse subtexto que fundamenta e guia os quadros Moving Pictures (Fotografias em Movimento), Mirrors (Espelhos) e Thunder (Trovão), respectivamente o primeiro, o quarto e o sétimo quadros, que foram objeto desta análise. Será apontado, a seguir, de que forma Lepage faz uso da narrativa de Madama Butterfly, mas para maior compreensão, consideramos que se faz necessária a descrição desses quadros.

\footnotetext{
${ }^{4}$ Tradução nossa.

${ }^{5}$ Moving Pictures (Fotografias em Movimento), Two Jeffreys (Dois Jeffreys), A wedding (Um casamento), Mirros (Espelhos), Words (Palavras), An Enterwiew (Entrevista) e Thunder (Trovão).
} 


\section{Moving pictures}

Em Moving Pictures, todas as cenas que marcam o encontro de Luke e Nozomi são chamadas de Hibakusha ${ }^{6}$, enumeradas por 1, 2, 3 e 4. O primeiro quadro se passa em Hiroshima, em 1945, dias após a explosão da bomba atômica. Luke O'Connor é um soldado americano enviado ao Japão para levantar estatísticas dos estragos causados pela explosão. Ele bate à porta, apresenta-se e pede a Nozomi que lhe permita fotografar o interior da casa. Ao conversarem um pouco, Luke descobre que ela fala inglês e gosta muito de revistas americanas. Na terça-feira à noite, Luke reencontra Nozomi, que o convida a entrar, pede que ele retire os sapatos e lhe oferece um cigarro. Quando Luke dela se aproxima para acender-lhe o cigarro, fica chocado ao observar o rosto da japonesa deformado pela explosão. Luke olha o quimono branco bordado com uma fênix dourada posicionado ao fundo da sala e Nozomi explica que aquele é seu quimono de casamento. Ela pergunta a Luke se ele também é casado e pede para ver uma foto de sua esposa e de seu filho, Jeffrey de cinco anos. Ele começa a fotografar a casa para desapontamento de Nozomi, que pensava que ele tiraria fotos dos danos das vítimas. No outro dia, percebendo a decepção da japonesa, Luke vai fotografá-la vestida em seu quimono de casamento. Enquanto eles bebem saquê, Nozomi lhe entrega um presente para o seu filho: uma boneca para que os jovens tenham boas esposas. Ao ser interrogada sobre o motivo de querer ser fotografada, Nozomi lhe explica o costume japonês: nos funerais se exibe uma fotografia escolhida pela pessoa. Ela mostra o desejo de que as pessoas vejam seu rosto como está, já que todas as suas fotografias são anteriores à bomba. Além disso, sua sogra escondeu os espelhos. Ao fim do quadro, as portas se fecham e as silhuetas sugerem que os dois trocam carícias, até que Luke recua, desculpando-se. Numa das cenas mais emocionantes da peça, Nozomi indaga a Luke se ele não a deseja porque é casado ou por causa de sua cicatriz. Ele responde que o problema não é a feiúra de Nozomi, mas a dele. Na cena seguinte Luke volta com a foto de Nozomi. Ela vê a fotografia, começa a chorar e pede para ficar sozinha. Ele ignora o pedido e entrega um batom de presente. Ela fica imóvel e

\footnotetext{
${ }^{6}$ Hibakusha é uma expressão japonesa utilizada para referir-se aos sobreviventes do ataque com a bomba atômica em 6 de agosto de 1945, na Segunda Guerra Mundial.
} 
deixa que Luke passe o batom em seus lábios. Eles se beijam. Depois de um blackout Luke e Nozomi deitados e seminus, se despedem sem saber se um dia se encontrarão novamente.

\section{Mirrors}

O quarto quadro, Mirrors, se inicia em 1986 também em Hiroshima. No prólogo, a personagem Ada Weber convida Jana Capek para uma visita à cidade. Jana aceita o convite e Ada a hospeda na casa de seu cunhado Jeffrey 2 , nascido da relação amorosa entre a japonesa Nozomi e o americano Luke, descrita acima. Na cena seguinte, já em Hiroshima, Jana está deitada de frente para um espelho em um dos quartos. Uma luz detrás dela revela a imagem de uma menina refletida na mesma posição. A peça nos transporta então para o ano de 1943 em Terezin ${ }^{7}$, na República Tcheca. Atrás da jovem Jana há uma fila de pessoas também refletidas pelo espelho. Elas estão andando, mas o ritmo dos passos acompanha o da música até que a caminhada se transforma em uma corrida. Um homem acorda a jovem e ela acompanha a multidão. A menina entra em um alojamento feminino e senta-se numa cama, quando uma mulher, falando alemão a expulsa de lá. Uma outra mulher intervém e leva a menina para sua cama. Em tcheco, Jana conta que tem 11 anos e pergunta o nome, a idade da mulher e o que é aquele livro que ela segura. Ela se apresenta como Sarah Weber, diz que tem 33 anos e que aquele é o libreto de uma ópera da qual ela é cantora. Em outra cena, voltamos à velha Jana que abre as portas do espelho, revelando outro jogo de espelhos. As luzes se apagam. Vêem-se mulheres dormindo e a menina sendo acordada por um homem que lhe tira medidas. Ele se apresenta como Maurice Zimmermann, um mágico francês, e convida Jana para participar de seu número da caixa mágica. Para isso ela precisaria apenas esconder-se por trás do espelho e a plateia pensaria que ela havia desaparecido. Jana aceita o convite e vai ao camarim de Sarah em busca de um figurino para sua apresentação. Lá vê um quimono branco com a fênix dourada, o mesmo usado por Nozomi no início do espetáculo. Jana indaga Sarah sobre o figurino e ela conta a história de Madama Butterfly. Sarah começa a chorar e a menina lhe pergunta se ela

\footnotetext{
7 Terezin é uma pequena cidade da República Tcheca que durante a Segunda Guerra serviu como campo
} de concentração nazista e que abrigava em sua maioria intelectuais e artistas judeus de toda a Europa. 
também tem um filho, como na ópera. Sarah diz que sim. Jana pergunta pelo nome. Sarah responde: Ada. Em seguida ouve-se a proibição de qualquer tipo de apresentação artística em Terezin. Já na Cruz Vermelha, Sarah retira sua ordem de deportação e sai com os outros prisioneiros. Maurice e Jana são chamados, mas não aparecem. Jana procura por Sarah e não a encontra. Pouco depois, à frente do espelho, vemos Jana adulta. A jovem Jana corre para o camarim de Sarah e encontra o corpo da cantora enforcado e grita. Ouve-se Madama Butterfly ao fundo. Um soldado chama os prisioneiros entregando um a um a ordem de deportação. Eles deixam sua bagagem no chão e entram no trem. Jana entrega sua ordem enquanto o soldado se distrai, entra na caixa de Maurice. $\mathrm{O}$ trem se fecha e Jana fica entre as bagagens que são retiradas por outro soldado. Na última cena do quadro, de volta a 1986, Jana ajoelha-se em frente ao espelho. Ele se abre mostrando Sarah vestindo o quimono e cantando Madama Butterfly. Em seguida ela pega um punhal, repete as últimas falas de Cio-Cio-San e apunhala-se.

\section{Thunder}

O último quadro de Os sete afluentes, Thunder nos traz a 1997 de volta à casa que pertenceu a Nozomi e onde agora mora Hanako, a viúva de Jeffrey 2. Hanako mora sozinha desde que o marido morrera e David, o filho do casal, mudara para Paris. Ela resolve então abrigar o jovem canadense Pierre Maltais que está no Japão para estudar Butoh ${ }^{8}$. Coincidentemente é o $60^{\circ}$ aniversário de Hanako e seu filho e amigos vão a Hiroshima para celebrar. David mostra-se contrariado com a ideia de receber o estudante, mas ao fim, ele e Pierre têm um rápido envolvimento amoroso. Na última cena de Thunder, $A$ dança do quimono, Pierre diz a Hanako que sua coreografia contará a história de uma hibakusha e pede um pouco de maquiagem emprestada. Pierre tira a camisa e Hanako começa a vesti-lo com o quimono de Nozomi. Mas, ao virar-se já é a velha Jana Capek vestindo Sarah Weber que estão em cena. Esta se vira para a plateia e seus lábios se movem como se cantasse algo de Madama Butterfly. Em seguida, dá as costas para o público e

\footnotetext{
${ }^{8}$ O Butoh é uma dança inspirada em movimentos de vanguarda e que surgiu no Japão pós-guerra criada por Tatsumi Hijikata em parceira com Kazuo Ohno.
} 
levanta os braços, escondendo sua cabeça no quimono. O quimono cai sobre os braços de Nozomi que está sentada num canto da sala. Luke aparece de pé, com a câmera sobre o rosto, de frente para a plateia. Ele toca o cabelo de Nozomi e a ajuda a se levantar. Dá um passo e tira sua foto. Ela joga o quimono para cima e quando ele cai já é Pierre quem o veste. Luke dá uma volta ao redor de Pierre e quando ele vira, Hanako aparece em seu lugar. Ela caminha até um canto onde se senta. Pierre vira e mostra o rosto pintado, iluminado pelas luzes. Ele começa sua apresentação do Butoh, como se fosse uma mulher, movendo-se graciosamente ao mesmo tempo em que manifesta expressões de horror e dor. Terminada a coreografia, Pierre desaba sobre os tatames. Hanako vai até ele, acaricia suas costas, caminhando em seguida para o seu quarto. Ouve-se o som de um trovão. Começa a chover, Pierre se levanta e tira o quimono, fecha as portas lentamente e faz menção de que vai para o seu quarto, mas entra no quarto de Hanako, fechando a porta. Por fim, um blackout.

\section{A Ópera Madama Butterfly}

Considerada uma das três mais populares óperas de todos os tempos, Madama Butterfly tem sido encenada, reencenada, evocada e reinventada desde que foi produzida pela primeira vez por Giácomo Puccini em 1904. Mas o que atrai o interesse dos autores e do público ao longo de todo esse tempo? Parte desse fascínio é perceptível pelo contato com o enredo da obra e o destino trágico da união entre Oriente e Ocidente.

No primeiro ato, o corretor de casamentos Goro, apresenta ao capitão-tenente da marinha americana Benjamim Franklin Pinkerton sua futura residência numa colina de Nagazaki, resultado de acordo que envolve também o aluguel da noiva, Cio-Cio-San por 999 anos sendo possível a qualquer momento, o cancelamento do mesmo. Durante a festa, Cio-Cio-San é renegada pela família por renunciar aos deuses ancestrais e ter se casado com um estrangeiro. Apesar de tudo, mostra-se bastante feliz. No ato seguinte, passados três anos desde o casamento, Pinkerton retorna aos Estados Unidos, deixando Butterfly sem saber que ela esperava um filho seu. O dinheiro está acabando, mas ela acredita que seu amado voltará. Suzuki, dama de companhia de Butterfly, reza para os deuses ancestrais, mas Butterfly, agora 
senhora Pinkerton, recusa-se a reassumir sua cultura. O embaixador americano Sharpless vai à casa de Cio-Cio-San trazendo uma carta que recebera de Pinkerton, ao mesmo tempo em que Goro traz uma nova proposta de casamento para Butterfly, agora com Yamadori, um admirador rico, alegando que a gueixa, por ter sido abandonada pelo marido, pode casar-se novamente. Cio-Cio-San recusa a oferta dizendo que seu marido voltará. Sharpless fica surpreso ao saber da existência do filho de Pinkerton e tenta revelar o conteúdo da carta que relata o novo casamento do americano. Butterfly interpreta erroneamente todas as frases que escuta e vê renovadas as esperanças da chegada do americano. Pinkerton retorna ao Japão acompanhado de sua esposa e visita Butterfly para anunciar que viera buscar seu filho. A tragédia se instala quando Cio-Cio-San diz que somente entregará a criança à Pinkerton. Sozinha, Butterfly retira de seus guardados um punhal do pai onde lê a inscrição "Com honra morre aquele que não mais com honra viver pode", matando-se em seguida. Pinkerton chega e ao vê-la morrendo chora angustiado, pronunciando seu nome três vezes.

\title{
A peça, a ópera e suas relações intermidiáticas
}

Para tentar compreender a relação de Os Sete Afluentes com Madama Butterfly precisamos perceber o texto ${ }^{9}$ da ópera sob dois pontos de vista distintos. No primeiro, observamos o amor trágico fadado à infelicidade, marca característica da ópera. Contudo, ao considerar a natureza plurimidiática dessa mídia que é formada pela combinação e justaposição de diferentes formas midiáticas, ou, como define Irina Rajewski, de combinação de mídias:

\begin{abstract}
A qualidade intermidiática dessa categoria é determinada pela constelação midiática que constitui um determinado produto de mídia, isto é, o resultado ou o próprio processo de combinar pelo menos duas mídias convencionalmente distintas, ou, mais exatamente, duas formas midiáticas de articulação. Cada uma dessas formas midiáticas de articulação está presente em sua própria materialidade e contribui, em sua própria maneira específica, para a
\end{abstract}

\footnotetext{
9 Tomo como texto a proposta de Claus Clüver que considera texto como um conjunto de signos necessariamente não verbais.
} 
constituição e significado do produto. (RAJEWSKY, 2012, p.24)

É possível, com isso, perceber que a dramaticidade e a teatralidade de Butterfly ultrapassam o romance e envolvem questões político-culturais na relação Ocidente e Oriente.

Se pensarmos na relação intermidiática estabelecida entre a peça e a ópera, podemos considerar que os três quadros apresentados encontram-se descritos na terceira subcategoria apresentada por Rajewski, de transposição intermidiática, que "usa seus próprios meios seja para se referir a uma obra individual específica produzida em outra mídia seja para se referir a um subsistema midiático específico." (RAJEWSKY, 2012, p. 24)

\section{Adaptação transcultural}

Lepage utiliza a relação entre Nozomi e Luke, entre Pierre, David e Hanako e a personagem Sarah para fazer referência ao que o artista define como "temática Butterfly". Entretanto, nos quadros Moving Pictures, Mirrors e Thunder, o processo de adaptação não se restringe às referências diretas como o quimono, a maquiagem, a música, e a própria apresentação da ópera. O compromisso com a fidelidade da transposição é preterido pela tentativa de se produzir um trabalho que não engesse a liberdade interpretativa da obra adaptada. É interessante saber que, na própria partitura de Madama Butterfly, há uma nota de Puccini que aponta o período histórico em que a ação se desenvolve: "atualidade", o que evidencia sua intenção de dialogar com a plateia sem o distanciamento temporal com esse público. Natural então, que, ao inspirar-se na ópera, Lepage fizesse as devidas substituições espaço-temporais de Butterfly. Mas o artista vai além e maneja também os comportamentos e estereótipos culturais. Ele cria o que Linda Hutcheon chama de adaptação transcultural.

Adaptações de uma cultura para outra não são eventos recentes, afinal de contas os romanos adaptaram os gregos. Mas a cultura da globalização aumentou a atenção para este tipo especial de adaptação que não apenas é a migração de uma cultura para outra, mas 
envolve a mudança de língua, de espaço e período. (HUTCHEON, 2006. p. 145)

Esse processo de (re-) interpretação e (re-)criação que constrói a adaptação pode envolver não apenas o deslocamento da mídia e do idioma, mas também a modificação do tempo, do espaço e do contexto histórico da obra inicial, permitindo atualizar elementos do trabalho que serve de inspiração para aproximar o tema das audiências contemporâneas, como podemos observar em Os Sete Afluentes. Para Carson (2000, p.44) esse seria justamente o grande mérito do trabalho artístico de Lepage: sua capacidade de agir como um espelho para nossa sociedade, captando as questões contemporâneas, capturando o espírito "de uma cultura transmitindo-o ao público de um modo pessoal e experimental".

O próprio quimono, marca da ópera e símbolo tão tradicional da feminilidade e da cultura japonesa ultrapassou a função de adereço e interligou todos os personagens no tempo e espaço. A história iniciou-se e encerrou-se por ele. E o romance entre Luke e Nozomi evoca não só a ópera, mas a marcação do Ocidente como o masculino (Luke O'Connor) e do Oriente como feminino (Nozomi) sob um novo ponto de vista que foge ao da submissão feminina diante do estrangeiro. Estamos em 1945, num Japão pósbomba atômica que tenta sobreviver em meio aos destroços e cuja invasão da cultura norte-americana já é perceptível. Butterfly era uma gueixa, frágil como a mulher desenhada nas porcelanas descritas na ópera. Nozomi, ao contrário, fala inglês, fuma e gosta de ler a revista "Time" ao mesmo tempo em que segue algumas tradições como o presente dado ao filho de Luke, o ritual de retirar os sapatos antes de entrar em casa e a fotografia para seu funeral. Existe também um paralelo entre os personagens masculinos nas duas obras, que têm pouco em comum, fora o fato de serem os dois soldados americanos em missão no Oriente. Luke - diferente de Pinkerton que não só descobre que é pai, como leva o filho embora - morre sem saber que nasceu uma criança do envolvimento dele com Nozomi. Mas Jeffrey 2, assim como o filho de Butterfly, também viaja à terra do pai. Lepage também aproveita o quadro para discutir o comportamento norte-americano em relação ao ataque em Hiroshima. Nozomi questiona o o levantamento dos danos que considera as 
casas e não as pessoas, como se para os Estados Unidos a devastação do espaço pudesse descartar a mensuração da destruição das vítimas. Indagação presente também no segundo quadro da peça, quando Luke é levado à corte marcial acusado de atividades anti-americanas ao manifestar-se contrário aos testes nucleares no Pacífico.

Em Espelhos, ao colocar Sarah como uma judia em pleno Holocausto, vivendo e ao mesmo tempo reencenando a história de Butterfly, percebemos jornadas e temáticas com algumas aproximações. Jana seria como Suzuki, ama de Butterfly, que está próxima à Sarah para lembrá-la de suas origens. Mas as circunstâncias que a obrigaram a separar-se da filha ultrapassam o dilema pessoal. A personagem Sarah e sua filha Ada representam milhares de famílias desfeitas durante as investidas nazistas contra os judeus no Holocausto. E, também, sua renúncia à vida não lembra em nada a gueixa com o coração partido. Vivendo em um campo de concentração, Sarah podia perceber que o final trágico era inevitável. Ao cantar a ária da cena de morte e repetir o ritual japonês do hara-kiri as palavras "Com honra morre aquele que não mais com honra viver pode" têm mais força.

\section{Considerações finais}

Uma das críticas à representação da relação Leste-Oeste é a de que o estrangeiro se vê seduzido pelos rituais da cultura do oriente, o que pode levar a uma idealização e até mesmo uma fetichização do mundo oriental. Lepage escapa desses desvios porque, ao mesmo tempo em que transforma Hiroshima numa terra onde devastação e renascimento coexistem, com grandes nuances de sensualidade, dá aos seus personagens japoneses colorações universais de pessoas que seguem as tradições de sua cultura, mas que são parecidos com qualquer outra pessoa em qualquer lugar do mundo. Aliás, é isso que permite as ligações intrincadas entre os personagens. Do contrário, estas soariam artificiais. No último quadro da peça, esse olhar estrangeiro sobre a cultura japonesa, representado por Pierre é mais evidente. Se Luke foi ao Japão registrar a destruição, Pierre chega a Hiroshima à procura da cultura e da beleza, uma beleza que se esconde dentro não fora, uma sensualidade mais fundamentada na essência que no estereótipo. Nozomi 
tem no rosto a marca da destruição, Hanako é uma sexagenária cega que se envolve com o jovem Pierre. Poderíamos dizer que é uma insinuação/homenagem de Lepage ao jovem Ocidente mais uma vez rendendo-se à experiência e tradição milenares do Oriente. Ou, que o título da cena final, seguido do sonoro trovão, represente o (re)começo que descrevi no início do artigo. Se depois da tempestade sempre há a calmaria, os personagens de Os Sete Afluentes parecem saber muito bem o que isso significa.

Espero que os quadros destacados tenham servido como demonstração do modo como Robert Lepage e o Ex Machina fazem a construção de seus trabalhos evidenciando sua visão de mundo contemporânea capaz de integrar assuntos aparentemente opostos na dissolução de fronteiras culturais, ao criar um teatro ao mesmo tempo provocador pela temática e pelo jogo que trava com suas fontes de inspiração e seus espectadores.

\section{Referências}

CARSON, Christie. The Dragons' Trilogy to The Seven Streams os the River Ota: The Intercultural Experiments of Robert Lepage in: Theater sans frontières: Essays on the Dramatic Universe of Robert Lepage, Michigan: Michigan State Universe Press, 2000.

CLUVER, Claus. Inter textus/Inter Artes/ Inter Media. In: Aletria n. 14. Belo Horizonte. EdUFMG, 2006.

FOUQUET, Ludovic. Robert Lepage - L'horizon en images. Québec: Éditions Les 400 coups, 2006.

HUTCHEON, Linda. A theory of adaptation. New York: Routledge, 2006.

LEPAGE, Robert. The Seven Streams Of River Ota. Londres: Methuen, 1996.

PUCCINI, Giacomo; ILLICA, Luigi; GIACOSA, Giuseppe; LONG, John Luther; BELASCO, David; CARIGNANI, Carlo. Madama Butterfly : tragedia giapponese in tre atti. Milano: Ricordi, 1977.

RAJEWSKY, Irina O. Intermidialidade, intertextualidade e "remediação": uma perspectiva literária sobre intermidialidade. Trad. Thaïs Flores Nogueira Diniz e Eliana Lourenço adsense de Lima Reis. In: DINIZ, Thaïs Flores Nogueira (Org.). Intermidialidades e estudos interartes: desafios da arte contemporânea. Belo Horizonte: UFMG, 2012.

Recebido em 30 de abril de 2017.

Aceito em 19 de maio de 2017. 